\title{
Vascular Endothelial Cells Promote Acute Plasticity in Ependymoglial Cells of the Neuroendocrine Brain
}

\author{
Sandrine De Seranno, ${ }^{1}$ Cecilia Estrella, ${ }^{1}$ Anne Loyens, ${ }^{1}$ Anda Cornea, ${ }^{2}$ Sergio R. 0jeda, ${ }^{2}$ Jean-Claude Beauvillain, ${ }^{1}$ and \\ Vincent Prevot ${ }^{1}$ \\ ${ }^{1}$ Institut National de la Santé et de la Recherche Médicale, Unité 422, Institut Fédératif de Recherche 114, 59045 Lille Cedex, France, and ${ }^{2}$ Division of \\ Neuroscience, Oregon National Primate Research Center-Oregon Health and Sciences University, Beaverton, Oregon 97006
}

\begin{abstract}
Glial and endothelial cells interact throughout the brain to define specific functional domains. Whether endothelial cells convey signals to glia in the mature brain is unknown but is amenable to examination in circumventricular organs. Here we report that purified endothelial cells of one of these organs, the median eminence of the hypothalamus, induce acute actin cytoskeleton remodeling in isolated ependymoglial cells and show that this plasticity is mediated by nitric oxide (NO), a diffusible factor. We found that both soluble guanylyl cyclase and cyclooxygenase products are involved in this endothelial-mediated control of ependymoglia cytoarchitecture. We also demonstrate by electron microscopy that activation of endogenous NO release in the median eminence induces rapid structural changes, allowing a direct access of neurosecretory axons containing gonadotropin-releasing hormone $(\mathrm{GnRH})$ (the neuropeptide controlling reproductive function) to the portal vasculature. Local in vivo inhibition of $\mathrm{NO}$ synthesis disrupts reproductive cyclicity, a process that requires a pulsatile, coordinated delivery of GnRH into the hypothalamic-adenohypophyseal portal system. Our results identify a previously unknown function for endothelial cells in inducing neuroglial plasticity and raise the intriguing possibility that endothelial cells throughout the brain may use a similar signaling mechanism to regulate glial-neuronal interactions.
\end{abstract}

Key words: glial cells; neuroglial plasticity; tanycytes; endothelial nitric oxide synthase; neurosecretion; hypothalamus

\section{Introduction}

In recent years, compelling evidence has been provided demonstrating that in addition to neuron-initiated signaling, nonneuronal cells play an important role in generating and regulating the flow of information within the brain (Haydon, 2001). Among these non-neuronal cells, astrocytes have been shown to play important roles in the control of both synaptic transmission (Parpura and Haydon, 2000; Lino et al., 2001; Oliet et al., 2001) and neurosecretion (Hatton, 1997; Theodosis, 2002; Ojeda et al., 2003). In addition to interacting with neurons, astroglial cells are in intimate contact with vascular endothelial cells throughout the nervous system (Simard et al., 2003). The extent and distribution of this relationship have led to the suggestion that glial and endothelial cells form local and higher-order "gliovascular units" that might contribute to establishing the structural and functional architecture of the brain (Nedergaard et al., 2003). Although

\footnotetext{
Received Aug. 6, 2004; revised Sept. 21, 2004; accepted Sept. 21, 2004.

This research was supported by Institut National de la Santé et de la Recherche Médicale (INSERM, France) Grant U422, the Universite de Lille 2 and its Imaging Core, the Fondation pour la Recherche Médicale, and by National Institutes of Health Grant HD25123, Cooperative Grant U54 HD18185 as part of the Specialized Cooperative Centers Programs in Reproduction Research, and Grant RR00163 for the Operation of the Oregon National Primate Research Center. S.D.S. was a PhD student supported by a fellowship from the French Ministère délégué à la Recherche et aux Nouvelles Technologies. C.E. was a postdoctoral research fellow supported by a grant from INSERM (poste vert) and the Institut Fédératif de Recherche 114. We thank Hugh C. Hemmings (Weill Medical College of Cornell University, New York, NY) for his generous supply of antibodies against DARPP-32 and Cord-Jean S. Edgell (University of North Carolina, (hapel Hill, NC) for kindly providing us with the EA.hy926 cell line.

Correspondence should be addressed to Dr. Vincent Prevot, Institut National de la Santé et de la Recherche Médicale, Unité 422, Place de Verdun, 59045 Lille Cedex, France. E-mail: prevot@lille.inserm.fr.

DOI:10.1523/JNEUROSCI.3228-04.2004

Copyright $\odot 2004$ Society for Neuroscience ～0270-6474/04/2410353-11\$15.00/0
}

some glial-derived factors affecting endothelial cell physiology have been identified (Zonta et al., 2003), the possibility that vascular endothelial cells themselves might convey signals to mature glial cells has not been addressed, perhaps because of the difficulties of identifying such events experimentally. These difficulties can be overcome by using an appropriate experimental model. Circumventricular organs of the brain, such as the median eminence of the hypothalamus, offer such a model because they contain an abundance of glial-endothelial contacts amenable to experimental scrutiny. Circumventricular organs are capable of sensing information reaching the brain via the bloodstream and, conversely, conveying information from the brain to the periphery via the release of neurohormones into the circulation (Cottrell and Ferguson, 2004). In addition to astroglial cells, circumventricular organs are endowed with modified ependymoglial cells (Palkovitz, 1987). These cells are particularly well developed in the median eminence of the hypothalamus, where they are known as tanycytes (Rutzel and Schiebler, 1980), and participate in the control of neurosecretion (Prevot et al., 2004).

The median eminence is the terminal field of neuroendocrine neurons that release their secretory products into the portal vasculature for delivery to the anterior pituitary gland. A dominant structural feature of this region is the abundance of tanycytes, the cell bodies of which line the ventral portion of the third ventricle and send long and slender processes that contact the endothelial wall of the fenestrated portal vessels, via "end-feet" specializations (Rutzel and Schiebler, 1980) similar to those of astrocytes contacting the microvasculature everywhere else in the brain 
(Simard et al., 2003). These end feet engulf neuroendocrine terminals, a structural arrangement that is most evident in the case of nerve endings containing gonadotropin-releasing hormone (GnRH) (Kozlowski and Coates, 1985; Meister et al., 1988), the neuropeptide that controls sexual maturation and adult reproductive function. Through the structural reorganization of their end feet, tanycytes regulate the direct access of GnRH nerve terminals to the vascular wall (King and Letourneau, 1994; Prevot et al., 1998, 1999a) and presumably modulate the release of GnRH into the portal vasculature.

Using the median eminence as a model for neuron-glia-endothelial cell interactions, we now report that vascular endothelial cells use a signaling pathway mediated by nitric oxide (NO) to regulate neuroglial plasticity at the $\mathrm{GnRH}$ neurovascular interface. Our findings reveal a distinct role for vascular endothelial cells in controlling the glial ensheathment of neurosecretory axonal terminals in the neuroendocrine brain and raise the possibility that such endothelial cell-to-glia signaling may be broadly used in the CNS to control glial plasticity.

\section{Materials and Methods Animals}

Sprague Dawley rats were purchased from Janvier (Saint Berthevin, France) and B \& K Universal (Fremont, CA). They were housed in a room with a controlled photoperiod ( $14 \mathrm{hr}$ of light and $10 \mathrm{hr}$ of darkness) and temperature $\left(23-25^{\circ} \mathrm{C}\right)$. Animals were allowed access to tap water and pelleted rat food ad libitum. They were used in accordance with the Institut National de la Santé et de la Recherche Médicale and National Institutes of Health Guidelines for the Care and Use of Laboratory Animals. All experiments were performed in accordance with the European Communities Council Directive on November 24, 1986 (86/609/EEC) regarding mammalian research, and the experimental protocols were approved by the Oregon National Research Center institutional research animal committee. Although part of the experiments performed on primary cultures of tanycytes, including cell transfection and time-lapse recording, were done in Oregon, all other experiments were conducted in France.

\section{Cell culture}

Primary cultures of tanycytes of the median eminence. Tanycytes were isolated from the median eminence of the hypothalamus of 10-d-old rats and cultured as described previously (Prevot et al., 2003b). After decapitation and removal of the brain, median eminences were dissected and crushed on $80 \mu \mathrm{m}$ nylon mesh (Sefar America Inc., Kansas City, MO) in DMEM and Ham's F12 (1:1) (DMEM/F12; Invitrogen, San Diego, CA) supplemented with $2 \%(\mathrm{v} / \mathrm{v})$ antibiotics (penicillin/streptomycin; Invitrogen). After enzymatic treatment with $10 \%(\mathrm{v} / \mathrm{v})$ trypsin/EDTA (1:1) (Invitrogen) for $5 \mathrm{~min}$ at $37^{\circ} \mathrm{C}$, cells were dissociated, centrifuged at $550 \times g$ for $4 \mathrm{~min}$, and then resuspended in DMEM/F12 supplemented with $10 \%(\mathrm{v} / \mathrm{v})$ donor calf serum (Invitrogen), $1 \%(\mathrm{v} / \mathrm{v})$ L-glutamine (Invitrogen), and 2\% penicillin/streptomycin. After suspension, singlecell dissociation was achieved by $8-10$ passages through a transfer pipette. Dissociated cells were plated in $75 \mathrm{~cm}^{2}$ culture flasks (Becton Dickinson Labware Europe, Meylan, France) at a final concentration of 20-25 median eminence tissue explants per flask and maintained under humid atmosphere of $5 \% \mathrm{CO}_{2}-95 \%$ air at $37^{\circ} \mathrm{C}$. Culture medium was changed after 3-4 d of culture and subsequently every $2 \mathrm{~d}$. On reaching confluence $(10-12 \mathrm{~d})$, the tanycytes were isolated from contaminating cells by overnight shaking at $250 \mathrm{rpm}$ at $37^{\circ} \mathrm{C}$ and either replated in $10 \mathrm{~cm}$ dishes for immunoprecipitation and/or Western blot experiments or seeded in culture plates on poly-L-lysine-coated glass coverslips for immunocytochemical, actin cytoskeleton remodeling and coculture experiments. After reaching $90 \%$ confluence, the medium was replaced by a tanycyte-defined medium (TDM) consisting of DMEM/F12 (devoid of phenol red; Invitrogen) supplemented with $1 \%$ L-glutamine, $2 \%$ penicillin/streptomycin, $5 \mu \mathrm{g} / \mathrm{ml}$ insulin (Sigma, Saint Quentin Fallavier, France), and $100 \mu \mathrm{m}$ putrescin (Sigma). The tanycytes were used $2 \mathrm{~d}$ later for the experiments.
Primary cultures of hypothalamic astrocytes. Hypothalamic astrocytes were purified from 2-d-old rats, as described previously (Dziedzic et al., 2003; Prevot et al., 2003a). After a growth period of $8-10 \mathrm{~d}$ in $75 \mathrm{~cm}^{2}$ culture flasks containing DMEM/F12 medium supplemented with $10 \%$ donor calf serum, $1 \%$ L-glutamine, and $2 \%$ penicillin/streptomycin, the astrocytes were isolated from contaminating cells by shaking the flasks at $250 \mathrm{rpm}$ at $37^{\circ} \mathrm{C}$ for one night, replacing the medium, and shaking again for a few hours. Astrocytes were then seeded onto poly-L-lysine-coated coverslips for immunocytochemical studies. After reaching $90 \%$ confluence, the medium was replaced by TDM. The astrocytes were used $2 \mathrm{~d}$ later for the experiments.

Purification of endothelial cells of the median eminence by sequential immunopanning. Endothelial cells of the median eminence (ECME) were isolated from 10-d-old rats using a procedure adapted from a protocol kindly provided by Dr. Ben Barres (Stanford, CA) (Mi et al., 2001). In brief, minced median eminence explants were enzymatically dissociated at $37^{\circ} \mathrm{C}$ for $90 \mathrm{~min}$ by using a papain solution $(33 \mathrm{U} / \mathrm{ml}$ ) (Worthington/ Cooper, Lakewood, NJ) in MEM/HEPES (Invitrogen) containing L-cysteine $(0.4 \mathrm{mg} / \mathrm{ml})$ (Sigma) and DNase $(125 \mathrm{U} / \mathrm{ml})$ (Sigma). Tissues were then triturated in a solution containing ovomucoid trypsin inhibitor solution $(2 \mathrm{mg} / \mathrm{ml})$ (Boehringer Mannheim, Mannheim, Germany), DNase $(125 \mathrm{U} / \mathrm{ml})$, and BSA $(1 \mathrm{mg} / \mathrm{ml})$ (Sigma) to get a suspension of single cells. The suspension was filtered through a $20 \mu \mathrm{m}$ nylon mesh. After centrifugation at $550 \times g$, single cells were successively panned on a Petri dish coated with an anti-CD90 mouse monoclonal antibody, which recognizes the rat Thyl.1 antigenic determinant (MRC-OX7; Serotec, Oxford, UK), to deplete macrophages and fibroblasts, and on a second Petri dish coated with rat neural antigen (RAN)-2 ascites (LGC Promochem, Molsheim, France) to deplete meningeal cells and type-1 astrocytes; the remaining cells were incubated in a Petri dish coated with Bandeiraea simplicifolia Lectin II (BSLII) (Vector Laboratories, Burlingame, CA), which binds to all vascular endothelial cells. The purified endothelial cells were cultured in DMEM supplemented with $10 \%$ fetal bovine serum, $1 \%$ L-glutamine, and $2 \%$ penicillin/streptomycin until they reached confluence. Then they were recovered by trypsin digestion from the last panning dish and plated in 12-well plates. For coculture experiments, cells were cultured $24 \mathrm{hr}$ before the experiment in TDM containing $1 \%$ fetal bovine serum.

Culture of EA.hy926 endothelial cell line. Endothelial cell line EA.hy926 was kindly provided by Dr. C. Edgell (University of North Carolina, Chapel Hill, NC). They derived this cell line by fusing human umbilical vein endothelial cells with the permanent human cell line A459 (Edgell et al., 1983), which is known to express endothelial NO synthase (eNOS) and to release NO spontaneously (Lindberg et al., 1996). They were cultured in DMEM supplemented with $10 \%$ fetal bovine serum, $1 \%$ L-glutamine, and $2 \%$ penicillin/streptomycin. Cells were cultured in TDM containing $1 \%$ fetal bovine serum $24 \mathrm{hr}$ before coculture experiments.

\section{Coculture of tanycytes with ECME or EA.hy926}

To document the ability of endothelial cells to induce actin cytoskeleton remodeling in tanycytes, the major glial cell type of the median eminence, cocultures of tanycytes with ECME or EA.hy926 were performed. Tanycytic cultures seeded on 18-mm-diameter coverslips coated with polyL-lysine were grown to $90 \%$ confluence and cultured for $2 \mathrm{~d}$ in TDM containing $1 \%$ fetal bovine serum. Tanycytes were then added to a confluent monolayer of vascular endothelial cell separated by glass chips in 12 -well plates and cultured for $30 \mathrm{~min}$ in fresh TDM plus $1 \%$ fetal bovine serum. Thereafter, tanycytes were fixed in $4 \%$ paraformaldehyde in $0.1 \mathrm{M}$ PBS, pH 7.4, for actin cytoskeleton visualization, and endothelial cells were processed for Western blot analysis (see below).

The ability of endothelial cells to promote actin cytoskeleton remodeling in tanycytes of the median eminence via NO release was examined by treating endothelial cell cultures either with $1 \mathrm{mM} \mathrm{N}^{\mathrm{G}}$-Nitro-Larginine methyl ester (L-NAME; Sigma), a nitric oxide synthase (NOS) inhibitor, or with $500 \mu \mathrm{M}$ L-arginine (L-Arg; Sigma), which is the precursor of NO synthesis and stimulates NOS activity. 


\section{Cell treatments}

To document the ability of $\mathrm{NO}$ to induce actin cytoskeleton modification in isolated tanycytes, $90 \%$ confluent cells cultured for $2 \mathrm{~d}$ in TDM were exposed to sodium nitroprusside (SNP; Sigma), which is an NO donor. Dose-response studies were performed with $\operatorname{SNP}(1,10,100,1000 \mathrm{~nm})$ to identify the concentration that had the optimal effect on actin cytoskeleton remodeling, without affecting cell viability. After $30 \mathrm{~min}$ of treatment, cultures were fixed with paraformaldehyde (4\%) in PBS and rinsed twice. Cells were permeabilized with $0.1 \%$ Triton X-100 for 5 min and then stained with Texas Red-X phalloidin (Molecular Probes, Eugene, OR), diluted 1:40 in PBS, for 45 min at room temperature. Phalloidin is a toxin that specifically recognizes the filamentous actin (F-actin). Culture slides were rinsed in PBS, and cell nuclei were stained with Hoechst (Molecular Probes).

To examine the possibility that SNP treatment may have toxic effects on cultured tanycytes, cells treated for 30 min were rinsed and cultured in fresh TDM medium for an additional $24 \mathrm{hr}$. Afterward, cells were fixed and either processed for actin cytoskeleton labeling or submitted to an in situ cell death detection kit [terminal deoxynucleotidyl transferasemediated biotinylated UTP nick end labeling (TUNEL)] according to manufacturer's instructions (Roche, Mannheim, Germany). Positive controls for TUNEL staining consisted of fixed-cell cultures treated with $10 \mu \mathrm{g} / \mathrm{ml}$ DNase I for $10 \mathrm{~min}$ at room temperature to induce DNA strand breaks. Fluorescein-dUTP labeling of DNA strand breaks was visualized with a Leica TCS SP confocal system, with a $25 \times$ numerical aperture (NA) 0.75 Plan FLUOTAR objective, using the $488 \mathrm{~nm}$ line of argon gas laser. The intensity of the laser beam and the sensitivity of the photodetector were kept constant to allow comparison between treatments. At least five optical fields per culture were examined.

To determine the importance of cyclooxygenase (COX) and soluble guanylate cyclase (sGC), which are two known targets of NO (Bredt and Snyder, 1992; Salvemini et al., 1993; Koesling and Friebe, 1999), in NOmediated actin cytoskeleton remodeling in tanycytes of the median eminence, tanycytes were treated with SNP for $30 \mathrm{~min}$ in the presence of 2 $\mu \mathrm{M} 1 \mathrm{H}-[1,2,4]$ oxadiazolo [4,3-a] quinoxalin-1-one (ODQ; Calbiochem, La Jolla, CA, and Meudon, France), a selective inhibitor of sGC, or $25 \mu \mathrm{M}$ indomethacin (Sigma), a selective blocker of COX. At the end of the treatment, the cells were processed for actin cytoskeleton staining.

\section{Determination of actin cytoskeleton remodeling}

Texas Red-X phalloidin-stained cultures were imaged using a coolPix camera (Roper Scientific, Tucson, AZ) attached to a Zeiss Axioscope fluorescent microscope and analyzed using MetaMorph 5.0 (Universal Imaging, West Chester, PA). For each culture chamber, three fluorescence images at different locations were recorded randomly at $400 \times$ magnification. The image resolution was set to $1276 \times 1016$ pixels and stored in TIF format. When the cells were confluent, each image contained $\sim 25-35$ cells visualized by Hoechst stain (data not shown). For each image, the total number of cells was counted. Then cells belonging to class 1 , class 2 , and class 3 were counted sequentially. With this method, each cell was counted only once and thus reported in only one group. The results obtained from the analysis of the three fields per chamber were added, and the percentage of cells belonging to each class was calculated. For each experimental condition, at least six chambers were analyzed, and the results were averaged. Each experiment was repeated at least three times in independent cultures. To avoid bias introduced by an observer, quantifications were repeated by an independent investigator unaware of experimental conditions.

\section{Cell transfection and time-lapse recording experiments}

Primary cultures of tanycytes were transfected with $2 \mu \mathrm{g}$ enhanced green fluorescent protein (pEGFP)-actin (Clontech, Palo Alto, CA), a vector that encodes a fusion protein consisting of the red-shifted, human codon-optimized variant of green fluorescent protein and the gene encoding human cytoplasmic $\beta$-actin. The cells were seeded into $60 \mathrm{~mm}$ culture chambers (MatTekCorp, Ashland, MA) containing a poly-Llysine-coated glass coverslip bottoms, grown to $80 \%$ confluence, and transfected for $3 \mathrm{hr}$ with Lipofectamin reagent (Invitrogen, Grand Island, $\mathrm{NY}$ ) in OptiMEM (Invitrogen). After transfection, the cells were cultured in TDM for $48 \mathrm{hr}$. Then the tanycytes maintained in Leibovitz's L15 medium (Invitrogen) without phenol red containing $5 \mu \mathrm{g} / \mathrm{ml}$ insulin and $100 \mu \mathrm{M}$ putrescine were placed under perfusion $\left(5 \mathrm{ml} / \mathrm{hr}\right.$ at $\left.37^{\circ} \mathrm{C}\right)$ in a temperature-controlled microscope stage microincubator (Harvard Apparatus, Holliston, MA). Living cells were imaged every 15 min for 30 min using a Leica TCS SP confocal system, with a $25 \times$ NA 0.75 PL FLUOTAR objective, using the $488 \mathrm{~nm}$ line of argon gas laser. Stack images were built in MetaMorph 5.0 (Universal Imaging).

\section{Fluorescent staining}

The brains of 10 -d-old rats were fixed by transcardiac perfusion with $4 \%$ paraformaldehyde in $0.1 \mathrm{M}$ PBS, pH 7.4, cryoprotected, and postfixed in the same fixative solution containing $20 \%$ sucrose overnight at $4^{\circ} \mathrm{C}$, embedded in Tissue Tek (Miles, Elkhart, IN), and frozen in liquid nitrogen. Cryostat sections $(14 \mu \mathrm{m})$ were mounted on chrome-alum-gelatincoated slides, air dried, and subjected to fluorescent staining using a procedure described previously (Prevot et al., 1998, 2003a). Briefly, the primary antisera were diluted in $0.02 \mathrm{M}$ potassium $\mathrm{PBS}, \mathrm{pH} 7.4$, containing $2 \%$ heat-inactivated normal goat serum and $0.3 \%$ Triton X-100 and incubated overnight at $4^{\circ} \mathrm{C}$ with sections. $\mathrm{GnRH}$ was detected with a rabbit polyclonal antibody (Beauvillain and Tramu, 1980) diluted 1:3000. Tanycytes of the median eminence were identified with a mouse monoclonal antibody to dopamine and cAMP-regulated phosphoprotein (DARPP)-32 \#C24-5a, kindly provided by Dr. Hugh Hemmings (Weill Medical College of Cornell University, New York, NY), diluted 1:20,000 (Ouimet et al., 1984; Hemmings and Greengard, 1986; Meister et al., 1988). The reactions were developed by incubation for $1 \mathrm{hr}$ at room temperature with FITC-conjugated goat anti-rabbit IgGs (1:400; Jackson ImmunoResearch, West Grove, PA), biotin-conjugated goat-anti mouse IgGs (1:500; Jackson ImmunoResearch), and then streptavidin-Alexa Fluor 633-conjugated goat anti-mouse IgGs (1:500; Molecular Probes). The vascular endothelial cells were visualized with tetramethylrhodamine isothiocyanate (TRITC)-conjugated Bandeiraea simplicifolia Lectin (1:600; Sigma). Cultured cells on coverslips were treated similarly. Astrocytes were identified with a rabbit polyclonal antibody to GFAP (1:1000; Dako, High Wycombe, UK). Sites of focal adhesion were visualized by using an anti-paxillin mouse monoclonal IgG, clone 5H11 $(10 \mu \mathrm{g} / \mathrm{ml}$; Upstate Biotechnology, Lake Placid, NY).

\section{Immunoprecipitation}

After treatment, cells in $10 \mathrm{~cm}$ dishes were rinsed with ice-cold PBS and snap frozen on dry ice. Cells were then thawed quickly, and proteins were immediately extracted with fresh lysis buffer $(25 \mathrm{~mm}$ Tris, pH 7.4, $50 \mathrm{~mm}$ $\beta$-glycerophosphate, $1 \%$ Triton X-100, 1.5 mm EGTA, 0.5 mm EDTA, 1 mu sodium pyrophosphate, $1 \mathrm{~mm}$ sodium orthovanadate, $10 \mu \mathrm{g} / \mathrm{ml}$ leupeptin and pepstatin A, $10 \mu \mathrm{g} / \mathrm{ml}$ aprotinin, $100 \mu \mathrm{g} / \mathrm{ml}$ PMSF). The protein content of cell extract was determined using the Bradford method (Bio-Rad, Hercules, CA). Equal amounts of protein (700-800 $\mu \mathrm{g})$ contained in a total volume of $750 \mu \mathrm{l}$ of lysis buffer were incubated with $4 \mu \mathrm{g}$ of anti-paxillin mouse monoclonal IgG (Upstate Biotechnology) with gentle rocking at $4^{\circ} \mathrm{C}$ for $2 \mathrm{hr}$. Thereafter, $20 \mu \mathrm{l}$ of protein-G agarose (Santa Cruz Biotechnology, Santa Cruz, CA) was added to the antibody-antigen complex and incubated for $1 \mathrm{hr}$ at room temperature. The agarose beads were collected by centrifugation, washed twice with ice-cold lysis buffer, and boiled for $5 \mathrm{~min}$ in $50 \mu \mathrm{l}$ of $2 \times$ sample buffer (187 mu Tris-base, 9\% SDS, 15\% glycerol, $15 \% \beta$-mercaptoethanol, and $86 \mu \mathrm{M}$ bromophenol blue, $\mathrm{pH} 6.8$ ). Samples were stored at $-80^{\circ} \mathrm{C}$ until use.

\section{Western blotting}

Samples were boiled again for $5 \mathrm{~min}$ after thawing and size-fractionated in $4-20 \%$ polyacrylamide-SDS precast gels (Invitrogen). After electrophoresis the proteins were transferred onto polyvinylidene difluoride (PVDF) membranes (Invitrogen) for $2 \mathrm{hr}$ on ice at room temperature. The membranes were blocked in $2.5 \%$ enzyme immunoassay-grade gelatin (Bio-Rad) in Tris-buffered saline (TBS; $0.05 \mathrm{M}$ Tris, pH 7.4, $0.15 \mathrm{M}$ $\mathrm{NaCl}$ ) for $1 \mathrm{hr}$ at $37^{\circ} \mathrm{C}$ and subjected to phosphotyrosine immunoblotting using the 4G10 monoclonal antibody $(1.5 \mu \mathrm{g} / \mathrm{ml}$; Upstate Biotechnology) overnight at room temperature. To develop the immunoreaction, the blots were incubated with horseradish peroxidase-conjugated 
secondary antibodies (Sigma) for $1 \mathrm{hr}$ at room temperature and developed using enhanced chemiluminescence (NEN, Boston, MA). After stripping ( $62.5 \mathrm{~mm}$ Tris $\mathrm{HCl}, \mathrm{pH}$ 6.7, 2\% SDS, $100 \mathrm{~mm} \beta$-mercaptoethanol; $30 \mathrm{~min}$ at $60^{\circ} \mathrm{C}$ ), the membranes were reprobed with a goat polyclonal antibody against actin (1:1000; Santa Cruz Biotechnology) or paxillin (1:500).

To characterize primary cell cultures, endothelial cells cultured in 12well plates were extracted in boiling $1 \times$ sample buffer, and glial cells cultured in $10 \mathrm{~cm}$ dishes were rinsed in ice-cold PBS, snap frozen on dry ice, and then quickly thawed; proteins were immediately extracted with fresh lysis buffer. After electrophoresis of an equal amount of proteins and transfer on PVDF membrane, blots were blocked in TBS containing $0.05 \%$ Tween 20 and $5 \%$ milk for $1 \mathrm{hr}$ at room temperature and exposed overnight at $4{ }^{\circ} \mathrm{C}$ either to an anti-DARPP-32 rabbit polyclonal antibody (1:1000; Cell Signaling Technology, Beverly, MA) or to an anti-eNOS rabbit polyclonal antibody, sc-654 (1:500; Santa Cruz Biotechnology).

\section{Assessment of ultrastructural changes induced by NO production in median eminence tissue}

To determine whether activation of endogenous NO production promotes morphological changes in the external zone of the median eminence, ex vivo experiments were performed. Female rats weighting $230-$ $250 \mathrm{gm}$ with regular estrous cycles were killed on the day of diestrus 2 (vide infra) by decapitation. After rapid removal of the brain, a block of neural tissue encompassing the periventricular zone of the tuberal region of the hypothalamus containing the median eminence was microdissected under a binocular magnifying glass. The hypothalamic explants, which were handled with care so that the median eminence was not damaged, were delineated by the posterior border of the optic chiasm, the anterior border of the mammillary bodies, and (laterally and dorsally) by the fornix. The total dissection time never exceeded $3 \mathrm{~min}$. Hypothalamic tissues were placed in six-well plates and preincubated $30 \mathrm{~min}$ at $37^{\circ} \mathrm{C}$ in $2 \mathrm{ml}$ of Krebs'-Ringer's bicarbonate buffer, $\mathrm{pH} 7.4$, containing $4.5 \mathrm{mg} / \mathrm{ml}$ D-dextrose, and $5 \mu \mathrm{M}$ tetrodotoxin to inhibit neurotransmitter release through the activation of voltage-gated sodium channels, under an air atmosphere containing $5 \% \mathrm{CO}_{2}$. After this preincubation period, tissues were placed in fresh medium containing either $500 \mu \mathrm{M}$ L-arginine (treated group; $n=3$ ), which stimulates the production of NO by endogenous NOS, or not (control group; $n=3$ ) for an additional $30 \mathrm{~min}$ incubation period. Explants were subsequently processed for electron microscopy as described previously (Prevot et al., 1998, 1999a). Briefly, tissues were fixed by immersion in a mixture of $2 \%$ paraformaldehyde, $0.2 \%$ picric acid, $0.1 \%$ glutaraldehyde, in $0.1 \mathrm{~m}$ phosphate buffer, $\mathrm{pH} 7.4$, for $2 \mathrm{hr}$ at $4^{\circ} \mathrm{C}$. Tissues were postfixed for $1 \mathrm{hr}$ at room temperature with $1 \% \mathrm{OsO}_{4}$ in phosphate buffer. After dehydration, pieces of tissue were embedded in Araldite. Semithin sections (1-2 $\mu \mathrm{m}$ thick) were used to progressively approach and identify the portion of the median eminence where the ultrastructural studies were performed, i.e. the area where the pituitary stalk becomes distinct from the base of the hypothalamus but still remains attached to it by the hypophysial portal vasculature system (Prevot et al., 1998, 1999a). This area, which does not extend $>20 \mu \mathrm{m}$, contains high numbers of GnRH fibers. To detect GnRH immunoreactivity, ultrathin sections ( $80-90 \mathrm{~nm}$ thick) collected on Parlodion $0.8 \%$ isoamyl acetate-coated 100 mesh grids (EMS, Fort Washington, PA) were treated using an immunogold procedure described previously (Prevot et al., 1998, 1999a). Briefly, after a preliminary treatment with $\mathrm{H}_{2} \mathrm{O}_{2}(10 \%$; $8 \mathrm{~min})$ and a blocking step in TBS $(0.1 \mathrm{M}$ Tris, $\mathrm{pH} 7.4,0.15 \mathrm{M} \mathrm{NaCl})$ containing $1 \%$ normal goat serum and $1 \%$ bovine albumin serum (TBSB) (10 min at room temperature), the grids were floated on a drop of the following reagents and washing solutions: (1) rabbit anti-GnRH (1: 5000 ) in TBSB for $60 \mathrm{hr}$ at $4^{\circ} \mathrm{C}$, (2) TBS to remove excess antibodies (three times for $10 \mathrm{~min}),(3)$ colloidal gold $(18 \mathrm{~nm}$ )-labeled goat antirabbit immunoglobulins (Jackson ImmunoResearch) 1:20 in TBS $(0.1 \mathrm{M}$ Tris, $\mathrm{pH} 7.4,0.5 \mathrm{M} \mathrm{NaCl}$ ) for $90 \mathrm{~min}$ at room temperature, (4) TBS (three times for $10 \mathrm{~min}$ ), and (5) distilled water (three times for $10 \mathrm{~min}$ ). The sections were also counterstained with uranyl acetate and lead citrate before observation. Studies on the specificity of the GnRH antisera have been described previously (Beauvillain and Tramu, 1980). Immuno- stained ultrathin sections were examined with a Zeiss transmission electron microscope 902 (Leo, Rueil-Malmaison, France).

\section{Intracerebral infusion of an inhibitor of NOS activity}

To determine the importance of functional NOS activity within the median eminence for the central control of the reproductive cycle, in vivo experiments were performed. L-NAME, an inhibitor of NOS activity, was chronically infused into the median eminence of the brain (bregma: -3.6 $\mathrm{mm}, 9.5 \mathrm{~mm}$ deep from the skull) (Paxinos and Watson, 1982) by a stereotaxically implanted infusion cannula (Plastics One, Roanoke, VA) connected to a subcutaneously implanted Alzet mini-osmotic pump (Alzet Corporation, Palo Alto, CA). The pumps (model 2002) have a flow rate of $0.5 \mu \mathrm{l} / \mathrm{h}$ and a capacity of $200 \mu \mathrm{l}$, resulting in a delivery period of $14-16 \mathrm{~d}$. Each pump was loaded with sterile $0.9 \% \mathrm{NaCl}$ containing $5 \mathrm{~mm}$ L-NAME or no L-NAME. After connection to the infusion device and overnight priming in $0.9 \% \mathrm{NaCl}$ at $37^{\circ} \mathrm{C}$, the assembly was implanted into a 230-250 gm rat with regular estrous cycles. Estrous cycle was monitored before and after surgery by daily inspection of vaginal cytology: diestrus 1 and 2 were defined by the presence of a predominance of leukocytes in the vaginal lavage, the day of proestrus was characterized by a predominance of nucleated rounded epithelial cells in vaginal smears, and the day of estrus was distinctively characterized by large numbers of cornified squamous epithelial cells, which occur in clusters. Subsequent to the infusion experiment, animals were killed to determine the implantation site of the cannula and assess exhaustion of the infusion solution.

\section{Statistics}

The differences between several groups were analyzed by one-way ANOVA followed by the Student-Newman-Keuls multiple comparison test for unequal replications. The level of significance was set at $p<0.05$. To compare percentages, groups were subjected to arc-sine transformation before statistical analysis to convert them from a binomial to a normal distribution.

\section{Results}

\section{Primary culture of tanycytes and purification of vascular endothelial cells from the rat median eminence}

To determine whether endothelial cells of the median eminence are capable of inducing tanycyte plasticity, we used a primary culture of tanycytes and developed a sequential panning method to purify vascular endothelial cells from the rat median eminence on postnatal day 10 (P10). Figure 1 shows in vivo characterization of tanycytes and endothelial cells within the median eminence at P10.

Like tanycytes in vivo (Meister et al., 1988), isolated tanycytes in culture express DARPP-32 (Fig. 2a). In contrast, neither hypothalamic astrocytes in vivo nor cultured hypothalamic astrocytes (Fig. 2a) contain DARPP-32 (Chauvet et al., 1996; Prevot et al., 2003b). To purify ECME, we incubated enzymatically dissociated P10 median eminence cells first on a panning dish coated with a monoclonal anti-Thy1.1 antibody to deplete microglia and meningeal fibroblasts (Mi and Barres, 1999) and second on a dish coated with a monoclonal anti-RAN-2 antibody to retain astrocytes and ependymal cells (Bartlett et al., 1981). The remaining floating cells were incubated on a third dish coated with BSLII, which selects endothelial cells (Mi et al., 2001). ECME were then removed from the BSLII-coated dish by trypsinization, seeded onto 12 -well plates, and grown to confluence.

In agreement with previous results in vivo (Prevot et al., 2000), purified ECME in culture expressed high levels of eNOS protein (Fig. $2 b$ ). The level of eNOS expression in ECME was comparable with those seen in EA.hy926 cells (Fig. 2b), a human endothelial cell line previously shown to express eNOS (Lindberg et al., 1996). In contrast, primary cultures of tanycytes were devoid of eNOS (Fig. 2b). The purity of ECME cultures was verified by immunocytochemistry using polyclonal antibody against von 


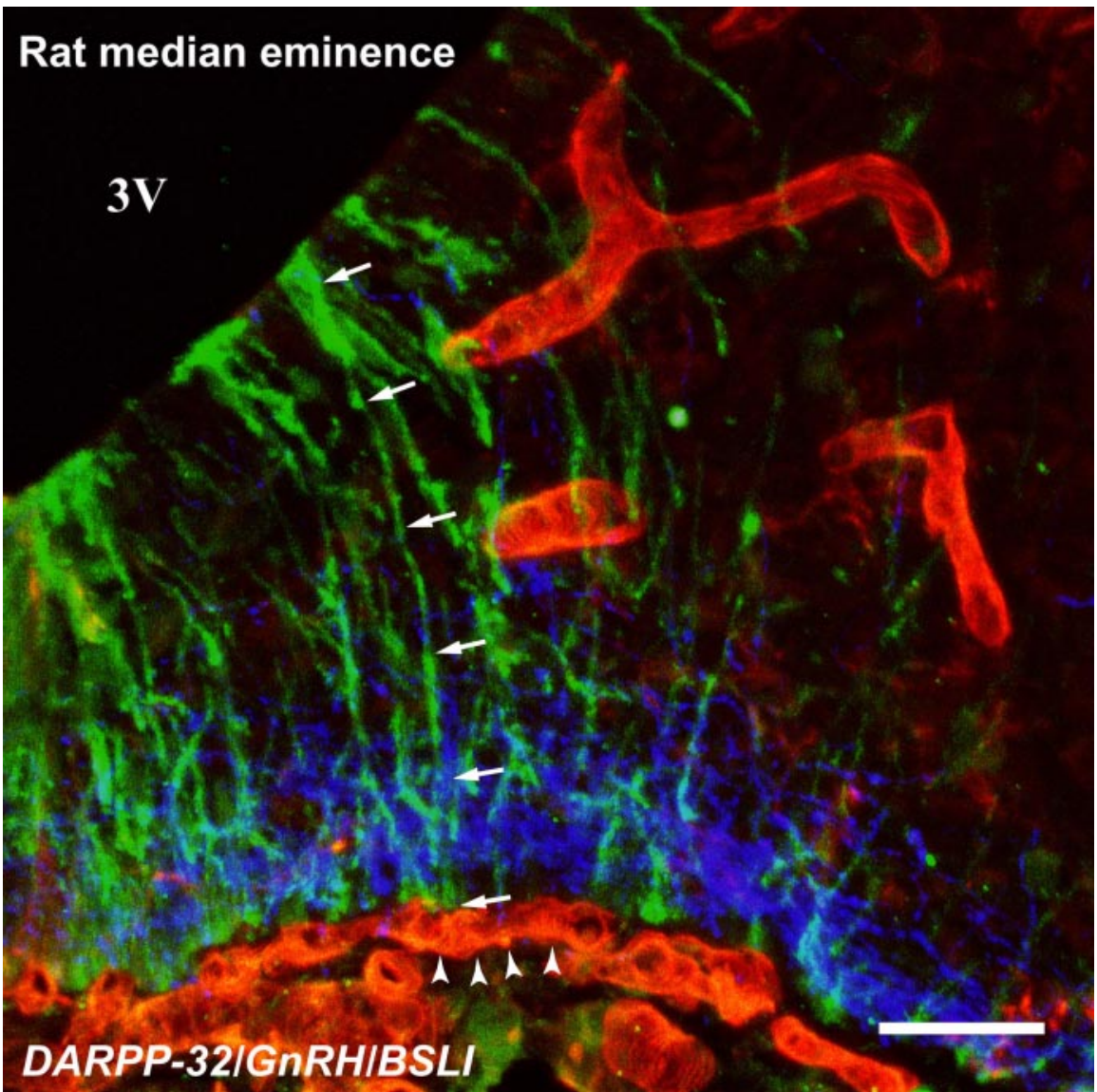

Figure 1. Confocal microscopy image showing the localization of DARPP-32 immunoreactivity (green; arrows) in tanycytes. These specialized radial ependymoglial cells of the median eminence send processes toward the vascular wall of the pituitary portal blood system. Vascular endothelial cells are labeled with TRITC-conjugated Bandeiraea simplicfolia Lectin (red; arrowheads). In the external zone of the median eminence, $\mathrm{GnRH}$ nerve terminals (blue) are in close proximity to DARPP-32immunoreactive tanycytic end feet that segregate most of the terminals from the portal capillaries. 3V, Third ventricle. Scale bar, $35 \mu \mathrm{m}$.

Willerbrandt factor that brightly stained $>95 \%$ of cultured ECME (data not shown). Moreover, ECME and EA.hy926 cells exhibited similar morphologies in confluent cultures (Fig. 2c).

\section{Purified endothelial cells of the median eminence promote rapid actin cytoskeleton remodeling in tanycytes via the release of a labile diffusible factor}

To investigate whether endothelial cells convey signals to ependymoglial cells capable of inducing the remodeling of their cytoarchitecture, we cultured tanycytes over a conditioning layer of purified ECME. The tanycytes were cultured on coverslips that were placed on top of the ECME monolayer so that the tanycyte monolayer faced toward the endothelial cells. After $30 \mathrm{~min}$, we stained the tanycytes with Texas Red-conjugated phalloidin to visualize F-actin. In control cells cultured without ECME, a substantial fraction of the actin filaments were located adjacent to the cell membrane (Fig. $3 a$, arrowheads), with a more diffuse localization to the cytoplasm. In contrast, in the presence of ECME, bundles of actin filaments formed heavy parallel stress fibers arranged along the entire longitudinal axis of the cell (Fig. $3 b$, arrows). We next exposed tanycytes to ECME-conditioned culture medium for $30 \mathrm{~min}$ (instead of ECME) and found that this treatment failed to promote stress-fiber formation (data not shown). Thus ECME appear to promote changes in tanycytic cytoskeleton via the release of a highly labile diffusible factor.
Because our previous studies showed that endothelial cells of the median eminence release spontaneously the gaseous messenger NO (for review, see Prevot et al., 2004), we tested the possibility that ECME-induced actin cytoskeleton remodeling in tanycytes was caused by NO. Pretreatment of endothelial cells with L-NAME (1 mM), an inhibitor of NO synthesis, prevented the formation of actin stress fibers in tanycytes cocultured with ECME (Fig. 3c). To verify that endothelial $\mathrm{NO}$ is able to promote changes in the actin cytoskeleton of tanycytes, we cocultured isolated ependymoglial cells with the endothelial cell line EA.hy926. These cells release NO spontaneously (Lindberg et al., 1996). Like purified ECME, EA.hy926 cells promoted L-NAME-sensitive formation of stress fibers in cocultured tanycytes (Fig. $3 d-f)$. To quantify the reorganization of actin cytoskeleton induced by endothelial cells, we classified the tanycytes into three different phenotypes according to the distribution of filamentous actin (Fig. 4a). These phenotypic classes were defined as follows. Class 1 comprised cells with cortical actin; in these cells actin is present mostly adjacent to the cell membrane. Few if any stress fibers are detected (Fig. 4a1). Stress fibers are parallel actin fibers transversing the cytoplasm along the major axis of the cell. Class 2 comprised cells with both cortical actin and light stress fibers (Fig. 4a2), and class 3 comprised cells without cortical actin and with heavy stress fibers (Fig. 4a3). Quantitative analysis showed that under basal control conditions, most tanycytes had an actin distribution typical of class 1 cells, i.e., with a predominance of the filaments near the cell membrane (Fig. 4b). In contrast, this distribution was observed only in a minority of tanycytes cocultured for $30 \mathrm{~min}$ with EA.hy926 cells (Fig. 4b). Instead, most EA.hy926-exposed tanycytes had the features of class 3 cells, i.e., with a predominance of actin filaments organized in heavy stress fibers (Fig. $4 b$ ). When tanycyte cocultures were treated with L-NAME to inhibit NO synthesis, there was a significant increase in class 1 cells, i.e., cells showing mostly cortical actin, and a concomitant reduction in the number of class 3 cells exhibiting mostly stress fibers (Fig. $4 b$ ). Thirty percent of cells in this group had the intermediate class 2 phenotype, i.e., showing both cortical actin and stress fibers (Fig. 3a2), but this number did not achieve statistical significance when compared with control cells $(20 \%$, class 2$)$ or tanycytes cocultured with EA.hy926 cells (10\%, class 2). These findings suggest that NO release is necessary for endothelial cells to promote rapid cytoskeleton remodeling in tanycytes.

\section{NO promotes acute remodeling of actin cytoskeleton in tanycytes}

To determine whether NO is able to trigger actin cytoskeleton remodeling in tanycytes of the median eminence on its own, 
tanycytic cultures were treated with different concentrations $(1,10,100$, and 1000 $\mathrm{nM}$ ) of SNP, an NO donor, for $30 \mathrm{~min}$ at $37^{\circ} \mathrm{C}$. Quantitative analysis revealed that although 1 and $10 \mathrm{~nm}$ SNP had no overt effect on actin cytoskeleton reorganization when compared with controls, 100 and $1000 \mathrm{~nm}$ SNP induced both the formation of heavy actin stress fibers and the disappearance of cortical actin in $>80 \%$ of the tanycytes (data not shown). To rule out the possibility of an SNP toxic effect, we treated tanycytes with SNP for 30 min and then cultured them in fresh TDM for an additional $24 \mathrm{hr}$ before examining them for programmed cell death. No DNA fragmentation was detected using either Hoechst 33342, a membrane-permeable DNA stain, or TUNEL staining (data not shown). SNP was then used at a $100 \mathrm{~nm}$ concentration in subsequent experiments. Figure $5 a$ shows that as in coculture experiments, actin cytoskeleton organization changed dramatically after the tanycytes were treated for $30 \mathrm{~min}$ with SNP. Although the majority of untreated tanycytes exhibited the actin cytoskeleton class 1 phenotype $(75.6 \pm 1.6 \%)$ (Fig. $5 a)$, most SNP-treated cells (79.5 $\pm 2.7 \%)$ adopted the actin cytoskeleton class 3 phenotype. Tanycytes analyzed $24 \mathrm{hr}$ after SNP treatment had partially recovered the basal actin cytoskeleton phenotype, with $41 \pm 5.2 \%$ of the cells being classified as class 1 phenotype and $41.2 \pm 4.4 \%$ as class 2 (data not shown).

To further dissect the effects of $\mathrm{NO}$ on tanycytic cytoarchitecture, we performed time-lapse experiments over a $30 \mathrm{~min}$ period on primary cultures of tanycytes transiently transfected with a construct expressing an actin-EGFP fusion protein. Figure $5 b$ shows fluorescent images of a cell imaged before (left panel), during (middle panel), and $30 \mathrm{~min}$ after (right panel) treatment with $100 \mathrm{~nm}$ SNP. Although transfected tanycytes overexpressed green fluorescent actin in both monomeric (G-actin) and polymeric forms (F-actin), giving rise to an increased background fluorescence (Fig. 5b), both stress fibers (arrows) and cortical actin (arrowheads) were clearly recognized and overlapped with F-actin detected by staining the cells with phalloidin after the timelapse study (data not shown). Within 15 min of treatment, the parallel stress fibers traversing the cell became more condensed (Fig. 5b, middle panel), and this change became more obvious after $30 \mathrm{~min}$ (Fig. $5 b$, right panel, arrows). At this time, it was apparent that some cortical actin filaments (Fig. 5b, left and middle panels, arrowheads) had moved inward to eventually form stress fibers (Fig. $5 b$ right panel, arrows).

a

C
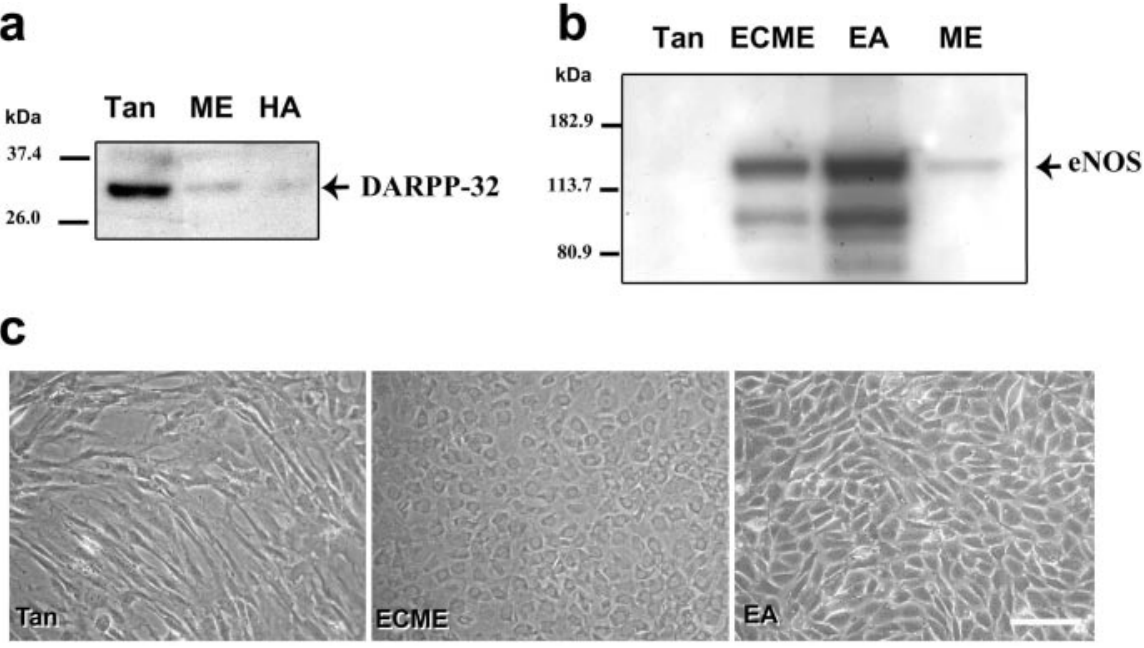

Figure 2. Characterization of cultured tanycytes and endothelial cells derived from the median eminence of the hypothalamus from 10-d-old rats. $a$, Western blot analysis of DARPP-32, a phosphoprotein specifically expressed in tanycytes (Meister et al., 1988), in primary cultures of tanycytes (Tan), cultured hypothalamic astrocytes (HA), and the median eminence (ME). Fifty micrograms of protein were loaded in each well. Note that although DARPP-32 is highly expressed in cultured tanycytes, its expression is barely detectable in primary cultures of hypothalamic astrocytes. $b$, Western blot analysis of eNOS in cultured tanycytes, purified vascular ECME, EA.hy926 endothelial cell line (EA), and the median eminence. c, Phase-contrast micrograph showing the morphology of tanycytes in culture, purified ECME, and EA.hy926 cell line. Although tanycytes in culture exhibit a thin and elongated shape, both ECME and EA.hy926 appear as small polygonal cells. Scale bar, $150 \mu \mathrm{m}$.
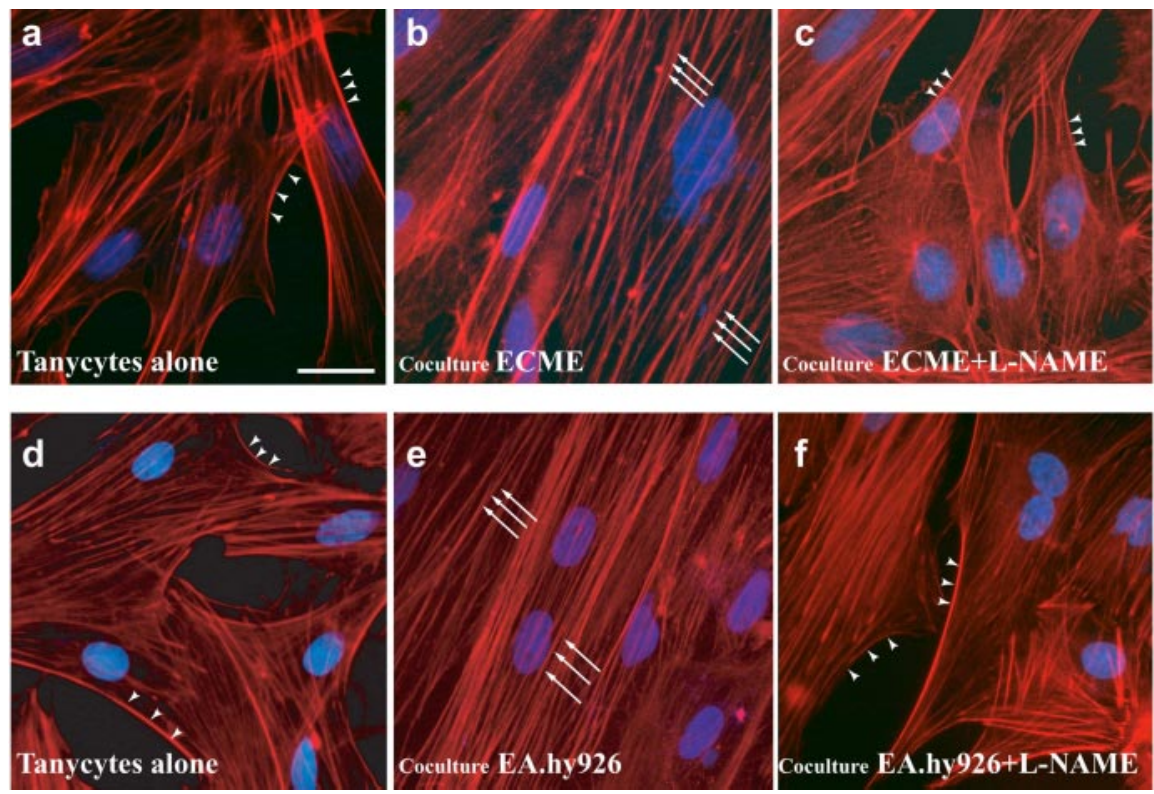

Figure 3. Ability of endothelial cells to promote plastic rearrangements of actin cytoskeleton in isolated tanycytes as assessed by coculture experiments. Tanycytes were cultured alone or suspended above a conditioning layer of purified ECME $(a-c)$ or EA.hy 926 cell line $(d-f)$ for 30 min and then stained with Texas Red-conjugated phalloidin to visualize filamentous actin (red) as well as with the Hoechst nuclear stain (blue). Under basal conditions, actin had a localization adjacent to the cell membrane (arrowheads) and also was diffused throughout the cytoplasm. In contrast, tanycytes cultured with endothelial cells for 30 min exhibited bundles of actin filaments forming parallel stress fibers (arrows) running over the length of the cells and did not exhibit cortical actin. These phenotypic changes were prevented by pretreating the endothelial cells with L-NAME (1 mM), indicating that endothelial cell-induced actin cytoskeleton remodeling in tanycytes was linked to NO secretion. Scale bar, $20 \mu \mathrm{m}$.

\section{NO-stimulated actin cytoskeleton remodeling in tanycytes requires both $\mathrm{sGC}$ and $\mathrm{COX}$ activities}

NO mediates most of its biological effects by binding to the prosthetic heme group of the enzyme NO-sensitive guanylyl cyclase, resulting in increased production of cGMP (Koesling and Friebe, 1999; Bredt, 2003). NO can also regulate the activity of COX 1 


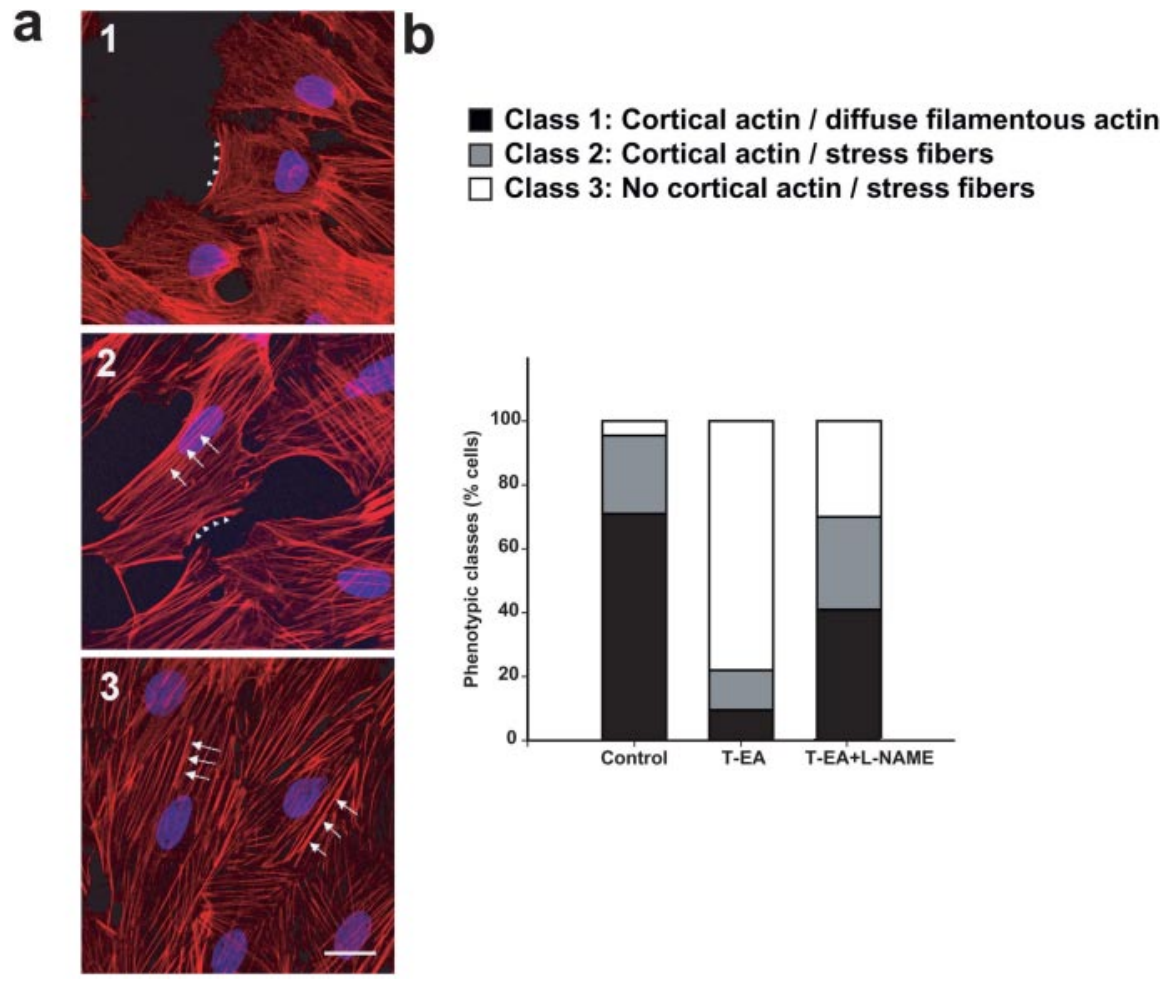

Figure 4. Quantitative analysis of actin cytoskeleton remodeling in tanycytes induced by endothelial cells. $a$, Characterization of three different phenotypic classes for tanycytes according to the organization of their filamentous actin cytoskeleton as visualized by staining with Texas Red-coupled phalloidin. Cell nuclei are stained with Hoechst (blue). Class 1 (1) corresponds to cells with cortical actin (arrowheads) and diffuse filamentous actin in the cytoplasm; class 2 (2) corresponds to cells with cortical actin (arrowheads) and stress fibers (arrows); class 3 (3) corresponds to cells with no cortical actin and heavy stress fibers (arrows). Scale bar, $20 \mu \mathrm{m} . b$, Quantitative analysis of the plastic changes observed in isolated tanycytes cultured with EA.hy 926 endothelial cell line for $30 \mathrm{~min}$, with or without L-NAME treatment. Changes are expressed as percentage of cells belonging to each phenotypic class. Control, Tanycytes alone; T-EA, tanycytes cocultured with EA.hy926; black bars, class 1; gray bars, class 2; white bars, class 3.

and 2, other heme-containing enzymes, and thus elicit prostaglandin release (Salvemini et al., 1993). To determine whether activation of sGC and/or COX is required for the NO-mediated actin cytoskeleton remodeling of tanycytes, we examined the effects of ODQ and indomethacin, two potent inhibitors of sGC and COX activities, respectively, on NO-induced tanycytic plasticity. Figure $5 a$ shows that both ODQ $(2 \mu \mathrm{M})$ and indomethacin $(25 \mu \mathrm{M})$ nearly abolished SNP-induced actin cytoskeleton remodeling in tanycytes, whereas ODQ and indomethacin had no effect on F-actin organization on their own (data not shown).

\section{NO-stimulated actin cytoskeleton remodeling in tanycytes is} associated with changes in focal adhesions

Because stress fibers are bundles of F-actin that end in focal adhesion points (Schmidt and Hall, 1998) and because paxillin is a multidomain adaptor involved in the temporospatial regulation of focal adhesion formation and actin cytoskeletal organization in motile cells (Turner, 2000), we investigated whether NOinduced reorganization of filamentous actin was parallel to changes in paxillin subcellular localization. Figure $6 a$ shows that SNP-induced formation of transcytoplasmic actin stress fibers is associated with the appearance of new points of focal adhesions. Although in control conditions paxillin coalesces into large clusters containing aggregated F-actin (Fig. $6 a$, large arrow), SNP treatment recruits paxillin immunoreactivity to multiple smaller clusters consisting of punctuated plaques to which actin stress fibers appear to be anchored (Fig. 6a, small arrows). Because paxillin phosphorylation by tyrosine kinases is important in reg- ulating the dynamics of focal adhesion and the associated actin network (Richardson et al., 1997), we determined whether the NO-coordinated macroaggregation of paxillin at focal adhesion points connected to actin stress fibers was associated with changes in tyrosine phosphorylation of paxillin. Figure $6 b$ shows that NO treatment results in decreased paxillin phosphorylation and that this decrease is prevented by blocking either sGC or COX enzyme activity with ODQ and indomethacin, respectively. Because a decrease in paxillin phosphorylation has been associated with enhanced cell motility (Yano et al., 2000), these findings suggest that endothelial NO increases tanycyte plasticity by forming focal adhesion points via a signaling pathway involving induction of sGC and/or COX activities and paxillin dephosphorylation.

\section{Activation of endogenous NO secretion induces morphological plasticity in the median eminence in situ}

To determine whether NO elicits morphological changes in tanycytes in situ as it does in vitro and whether such changes impact neuron-glia interactions in the median eminence, we studied the effect of endogenous NO production on the association of tanycytes with GnRH nerve endings at the ultrastructural level. Hypothalamic explants containing the median eminence were treated for $30 \mathrm{~min}$ with L-arginine $(500 \mu \mathrm{M})$, a well established activator of eNOS (Hardy and May, 2002), and then processed for electron microscopy (Fig. 7). We used hypothalamic explants from rats killed on the day of diestrus, a phase of the estrous cycle when direct access of GnRH nerve terminals to the portal vasculature is prevented by the presence of tanycytic end feet (Prevot et al., 1998, 1999a). Ultrastructural examination of GnRH-immunoreactive fibers in 15-20 ultrathin sections per explant revealed that L-arginine treatment resulted in the formation of neurohemal junctions between $\mathrm{GnRH}$ axons and endothelial cells of the median eminence (Fig. $7 b$ ). In contrast, and in agreement with our previous results (Prevot et al., 1998, 1999a), no such structural relationship was detected in untreated hypothalamic explants (Fig. 7a). In the absence of treatment, GnRH fibers were away from the pericapillary space and were often enwrapped by a single tanycytic end foot (Fig. 7a). In the presence of L-arginine, many GnRH nerve endings were found to be in close proximity to the parenchymatous basal lamina that delineates the pericapillary space (Fig. $7 b$, white arrow). In these areas tanycytic processes were much less conspicuous (Fig. 7b, black arrows). The GnRH neuron-endothelial cell connections were most often established at basal laminapericapillary space evaginations (Fig. $7 b$, white arrow). These evaginations also appeared occasionally in the nervous parenchyma in the immediate proximity of $\mathrm{GnRH}$ axon terminals after L-arginine treatment (data not shown), suggesting that tanycytic processes were undergoing morphological changes at these precise locations. 
a
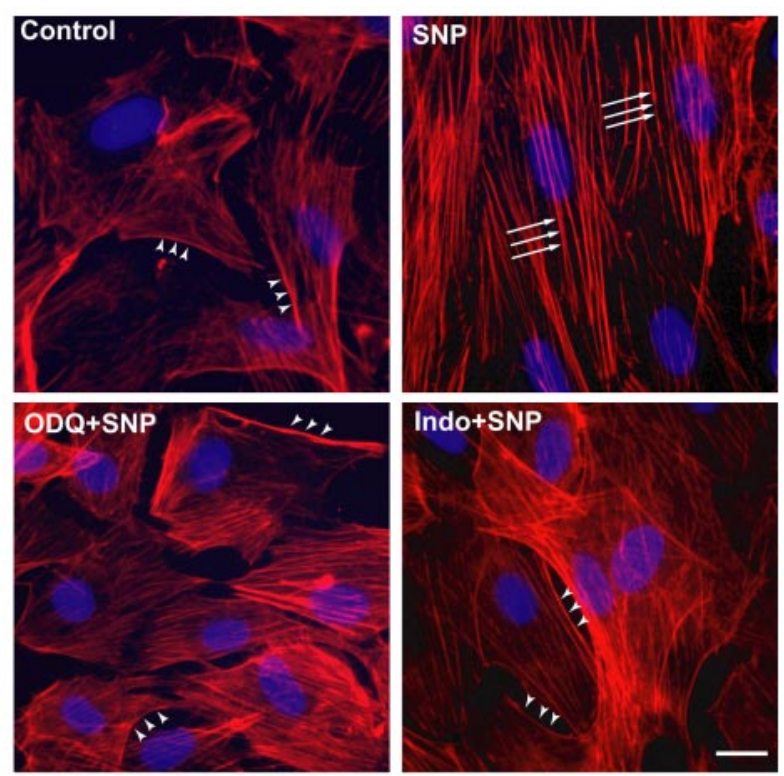

Class 1: Cortical actin / diffuse filamentous actin Class 2: Cortical actin / stress fibers

$\square$ Class 3: No cortical actin / stress fibers

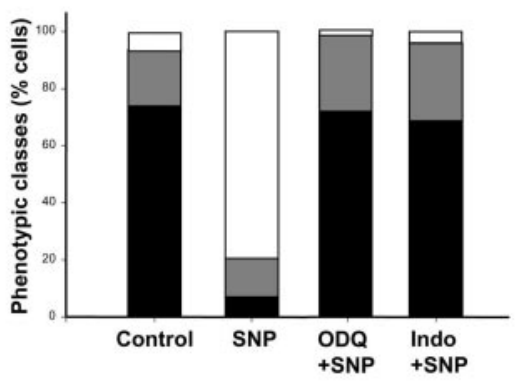

b
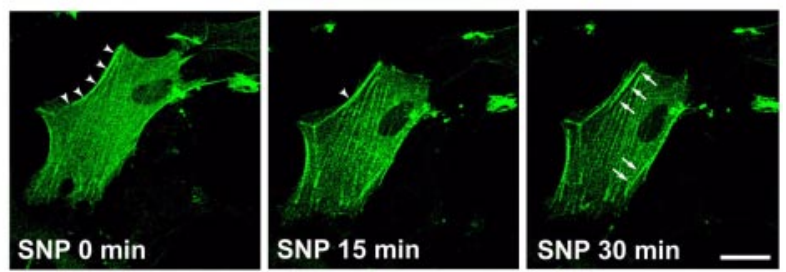

Figure 5. N0 promotes actin cytoskeleton remodeling in cultured tanycytes and requires both SGC and COX activities to exert these effects. $a$, SNP ( $100 \mathrm{~nm} ; 30 \mathrm{~min}$ ), an NO donor, was sufficient to induce dramatic actin cytoskeleton remodeling in tanycytes cultured in tanycytedefined medium. SNP caused the disappearance of cortical actin (arrowheads) and the formation of stress fibers (arrows). Blockade of $\mathrm{SGC}$ and $\mathrm{COX}$ activities abolished the effect of SNP on actin cytoskeleton remodeling. To block $\mathrm{SGC}$ and $\mathrm{COX}$ activities, tanycyte cultures were pretreated for 30 min with ODQ $(2 \mu \mathrm{M})$ and indomethacin $(25 \mu \mathrm{M})$, respectively, and incubated for an additional $30 \mathrm{~min}$ in the presence of SNP ( $100 \mathrm{~nm})$. Concomitant treatment of tanycytes with SNP and either SGC or COX inhibitors abrogated the ability of SNP to cause cortical actin (arrowheads) to disappear and to promote actin stress fiber formation (arrows). Texas Red-conjugated phalloidin was used to visualize filamentous actin (red), and Hoechst was used to stain nuclei (blue). Quantitative analysis of the plastic changes elicited by SNP and their inhibition is shown in the bar graph ( $n=3$ independent cultures). Scale bars, $15 \mu \mathrm{m}$. $b$, Time-lapse recording of SNP effects on primary cultures of tanycytes transiently transfected with a construct expressing actin-EGFP fusion protein. Both G-actin and F-actin were visualized by fluorescent microscopy (green puncta in the background and green filaments, respectively). The same cell was imaged before (left panel) and at 15 and $30 \mathrm{~min}$ after the initiation of SNP treatment (middle and right panels, respectively). SNP (100 nM) promotes cortical actin filaments (arrowheads) to gradually move inward and form actin stress fibers traversing the cell (arrows). SNP treatment also caused formation of parallel actin stress fibers in transfected tanycytes (30 vs $0 \mathrm{~min}$ ). Scale bar, $20 \mu \mathrm{m}$. a
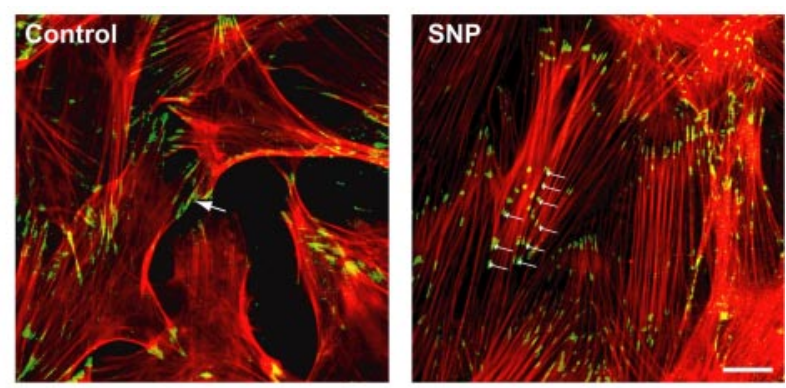

b

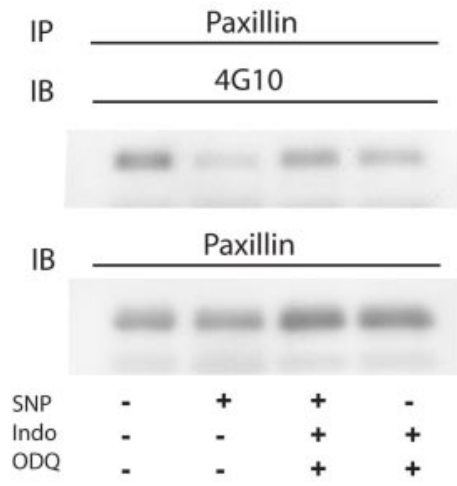

Figure 6. Effect of $\mathrm{N} 0$ donors on focal adhesion reorganization and paxillin phosphorylation in cultured tanycytes. $a$, Immunofluorescent microscopy localization of paxillin (green) in cultured tanycytes. Under control conditions, paxillin coalesces into large structures that contain aggregated F-actin (red; arrows). SNP treatment recruits paxillin immunoreactivity to a type of structure consisting of punctuate plaques to which actin stress fibers are anchored (small arrows). Scale bars, $20 \mu \mathrm{m} . b$, Treatment of tanycytes with SNP results in lower levels of paxillin tyrosine phosphorylation. Tanycytes were cultured in tanycyte-defined medium and exposed to SNP (100 nM) for $30 \mathrm{~min}$. Pretreatment of tanycyte cultures with both ODQ $(2 \mu \mathrm{M})$ and indomethacin $(25 \mu \mathrm{M})$ for 30 min blocked SNP-induced changes in paxillin phosphorylation. Proteins were collected after treatment and immunoprecipitated (IP) with a specific paxillin antibody, electrophoresed to size fractionate the immunoprecipitated species, and immunoblotted (IB) with antibodies to phosphotyrosine (4G10). Then immunoblots were stripped and reprobed with the antibody to paxillin. A representative blot from four independent experiments is shown.

Infusion of an NO synthesis inhibitor targeted to the median eminence disrupts female reproductive cyclicity

To determine the physiological importance of median eminence NO signaling in the control of mature reproductive function, adult female rats with regular estrous cycles were treated with L-NAME, the NOS inhibitor used in the in vitro studies. The compound was applied to the median eminence of the hypothalamus (Fig. 8a) via a cannula connected to a subcutaneously implanted osmotic minipump. Examination of the estrous cycle during 2 weeks subsequent to the initiation of the treatment showed disruption of estrous cyclicity within a few days of infusion $(n=6)$ (Fig. 8). L-NAME-infused rats showed a preponderance of days in the diestrous phase of the cycle and a concomitant reduction of days in proestrus and estrus. In contrast, control animals infused with the L-NAME vehicle had normal 4 d estrous cycles $(n=5)$ (Fig. 8b). Importantly, after the content of the pump was exhausted (i.e., after $14 \mathrm{~d}$ of infusion), animals treated with the NOS inhibitor that were allowed to survive an additional week recovered normal estrous cyclicity (Fig. $8 b, c$, recovery) $(n=$ 3). L-NAME infusions rostral to the median eminence area, in the ventral part of the periventricular zone of the anterior region of the hypothalamus [retrochiasmatic ( $\mathrm{RCh}$ ) area], which is devoid of GnRH nerve terminals and cell bodies, did not reproduce the 


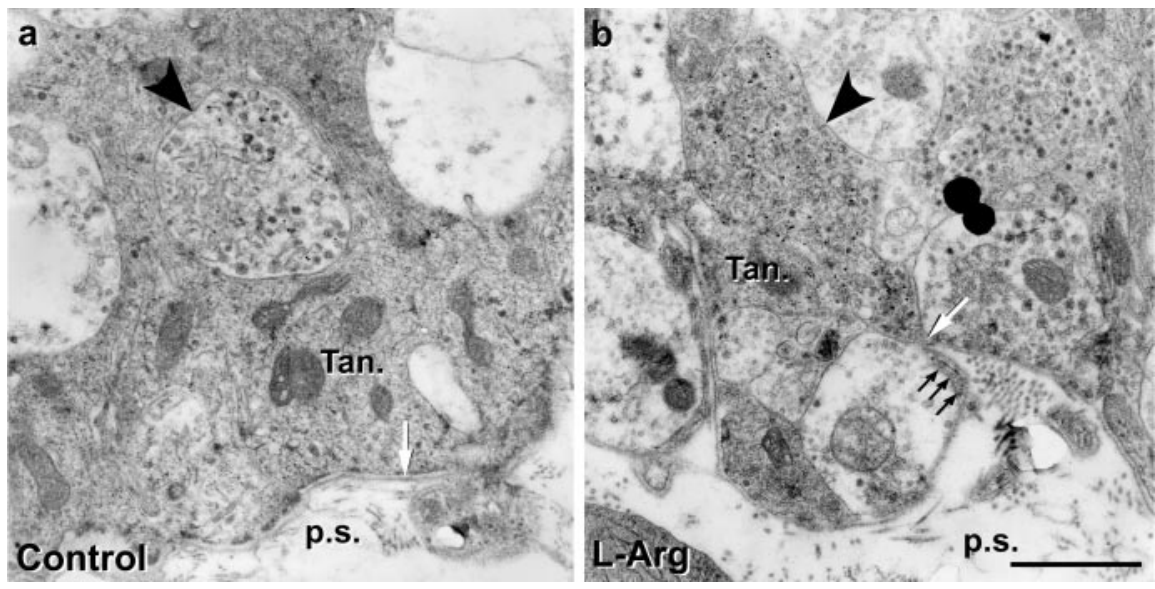

Figure 7. Activation of endogenous NO secretion in the median eminence of the hypothalamus induces ultrastructural changes, allowing $\mathrm{GnRH}$ nerve terminals to form direct neurovascular junctions. Representative electron micrographs of GnRHimmunoreactive nerve terminals ( $15 \mathrm{~nm}$ gold particles; black arrowhead) from female rat median eminence explants incubated 30 min in the presence $(b)$ or absence $(a)$ of $\mathrm{L}-\operatorname{Arg}(500 \mu \mathrm{M})$. Under basal unstimulated conditions (control), the GnRH axonal endings (black arrowhead) were separated from the pericapillary space (p.s.) (delineated by the parenchymatous basal lamina; white arrow). Most of the nerve endings were enwrapped by single tanycytic end feet (Tan.), and none was seen to contact directly the basal lamina in three independent explants. GnRH nerve terminals forming neurovascular junctions (i.e., contacting directly the pericapillary space) (c, white arrow), were detected in each L-Arg-treated median eminence explant $(n=3)$. Very few tanycytic processes remained around those $\mathrm{GnRH}$ nerve endings that had direct access to the pericapillary space (black arrows). Noticeable neurohemal junctions were established most often at basal lamina-pericapillary space evaginations (white arrow). Scale bars, $1 \mu \mathrm{m}$.

disruptive effect of the median eminence infusions $(n=3)$ (Fig. $8 c)$. These results indicate that NO secretion within the median eminence and the changes in the glia-neuronal-endothelial relationship that occur as a result of $\mathrm{NO}$ actions are required for the normalcy of female reproductive cyclicity.

\section{Discussion}

The present study identifies vascular endothelial cells as a new regulatory component of brain plasticity. Our results show that endothelial cells promote acute morphological changes in ependymoglial cells of the median eminence and thus provide a significant regulatory input to the dynamic interaction that exists between these cells and neurosecretory axons of the neuroendocrine brain. We show that endothelial cells affect plasticity, at least in part, through the diffusion of the labile factor NO. Previous studies have suggested that NO is a short-action rapidly diffusible mediator of "volume" transmission (Agnati et al., 1995) capable of coordinating neuroglial inputs in a restricted brain volume via activation of multiple cytosolic enzymes (Gally et al., 1990; Bredt and Snyder, 1992). Our results are in keeping with this view. Moreover, by demonstrating the ability of endothelial cells to regulate the access of neurosecretory axons to the blood stream, they define the median eminence of the hypothalamus as a functional brain microdomain (Nedergaard et al., 2003; Zonta et al., 2003) in which endothelial and glial cells interact to regulate neuronal activity.

Endothelial cells of the median eminence use a signaling pathway mediated by NO to promote cytoarchitectural changes in ependymoglial cells. The dynamic changes in the assembly of focal adhesions and the concomitant recruitment of actin stress fibers induced by $\mathrm{NO}$ are a prerequisite for changes in cell shape (Turner, 2000) and may thus provide a driving force for acute cell movement (Tapon and Hall, 1997) in tanycytes. The finding that the inhibition of either sGC or COX abrogated both NOmediated actin cytoskeleton remodeling and changes in focal ad- hesions in tanycytes indicates that the intracellular mechanisms underlying the stimulatory effect of $\mathrm{NO}$ on tanycyte plasticity involve the participation of both cGMP and prostaglandins-thromboxanes. Cyclooxygenase products are also involved in the control of "long-term," growth factor-induced ependymoglial cell plasticity because they are required for TGF $\alpha$ to elicit sequential changes in outgrowth and retraction of tanycytic processes over a $24 \mathrm{hr}$ period (Prevot et al., 2003b). Thus ependymoglial cell plasticity appears to be under the control of two complementary mechanisms. One, set in motion by endothelial cells within minutes, requires the rapid actions of $\mathrm{NO}$; the other, initiated by astroglial cells and tanycytes themselves, becomes apparent after a lag time of hours rather than minutes and involves the activation of $\mathrm{TGF} \alpha-$ erbB-1 receptor-dependent signaling (Prevot et al., 2003b).

In addition to providing direct evidence for an involvement of cyclooxygenase products in eliciting ependymoglial cell plasticity, our results indicate that endothelial NO also facilitates axonal remodeling. In vitro activation of NO production results in advancement of GnRH secretory terminals toward the pericapillary space of the median eminence. Conversely, in vivo blockade of NO synthesis arrests estrous cyclicity in the diestrous stage, a phase of the cycle in which $\mathrm{GnRH}$ axons are enwrapped by tanycytic end feet (Prevot et al., 1998, 1999a) and thus are kept away from the portal vasculature. Although the present studies do not conclusively identify the downstream events underlying these $\mathrm{NO}$-dependent effects on axonal plasticity, the ability of endothelial NO to activate sGC in tanycytes implicates these cells as intermediates and cGMP as an effector molecule. The recent demonstration of an involvement of NOcGMP signaling in axonal elongation and/or growth cone orientation (Song et al., 1998; Seidel and Bicker, 2000; Nishiyama et al., 2003 ) supports this interpretation. Furthermore, although inferential, support for this view is provided by a recent report (Wark et al., 2002) showing that NO released in response to synaptic activity promotes synaptic formation in retinal ganglion cells in vitro and that this effect requires glial intermediary. Although by definition neurosecretory neurons projecting to the median eminence do not communicate with non-neural target cells via synaptic contacts, they do form well defined neurovascular junctions with endothelial cells of the portal vasculature. As such, and for mechanistic purposes, these junctions can be considered the neuroendocrine counterpart of synaptic contacts.

The physiological importance of the aforementioned NOmediated cell-cell communication processes is highlighted by the results of our in vivo studies showing that targeted blockade of NO release from the median eminence resulted in disruption of female reproductive cyclicity. The estrous cycle of animals injected with L-NAME, an NO synthesis blocker, remained suspended at the diestrous phase, a stage during which $\mathrm{GnRH}$ release is low (Levine and Ramirez, 1982) and direct contacts between GnRH axon terminals and endothelial cells are not detected (Prevot et al., 1998, 1999a). 
a
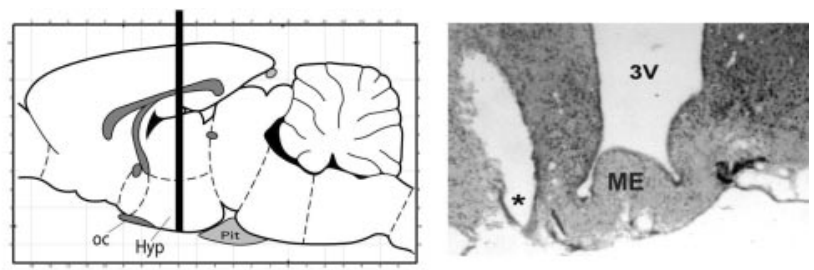

b

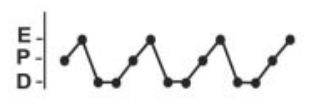

$\mathrm{NaCl}$

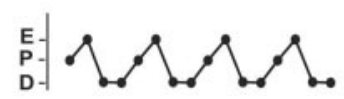

$\mathrm{NaCl}$

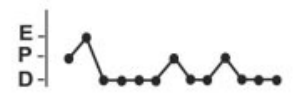

L-NAME

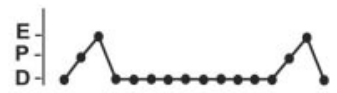

L-NAME

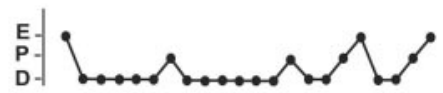

L-NAME and recovery
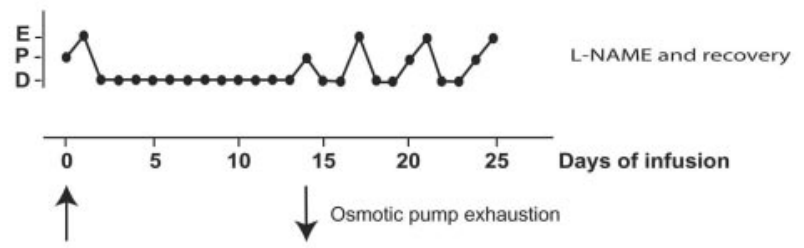

C

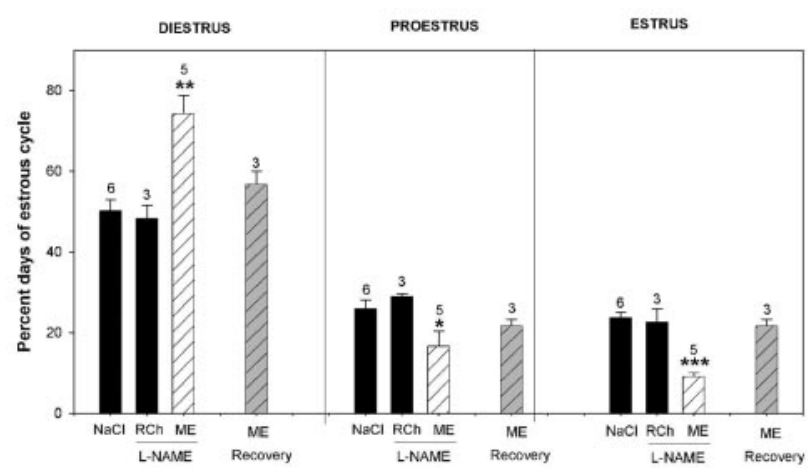

Figure 8. Effect of pharmacological blockade of NO synthesis targeted to the median eminence of the hypothalamus on female reproductive cyclicity. $a$, Drawing and photomicrograph of sagittal (left) and coronal (right) sections, respectively, showing the anatomical localization of the implantation site (right panel, asterisk). L-NAME ( $5 \mathrm{~mm}$ ), the NOS inhibitor used in our in vitro experiments, or vehicle ( $\mathrm{NaCl} 0.9 \%$ ) was delivered via a stereotaxically implanted stainless steel cannula connected to a subcutaneously placed osmotic pump delivering its contents at a rate of $0.5 \mu \mathrm{l} / \mathrm{hr}$ for $14 \mathrm{~d}$. oc, Optic chiasm; Hyp, hypothalamus; Pit, pituitary; $3 \mathrm{~V}$, third ventricle; $\mathrm{ME}$, median eminence. $b$, Disruption of estrous cyclicity in young adult rats by the infusion of L-NAME into the median eminence of the hypothalamus. Infusion starts at day 0 (arrow pointing up) and ends $14 \mathrm{~d}$ later (arrow pointing down), when the pump content is exhausted. The estrous cycle profiles of representative animals are depicted. D, Diestrus; E, estrus, P, proestrus. C, Analysis of the alterations in estrous cyclicity caused by L-NAME infusion into the ME or RCh region of the hypothalamus. This region contains neither GnRH cell bodies nor GnRH axonal terminals. Animals infused with L-NAME in the ME stayed a significantly greater percentage of days in diestrus and exhibited significantly fewer days in proestrus and estrus. L-NAME had no effect when infused into the $R C h$ area. Animals that were allowed to survive after pump exhaustion had all three stages of the estrous cycle restored to control values (ME recovery). ${ }^{*} p<0.05$ versus "NaCl" and "L-NAME-RCh" groups; ${ }^{* *} p<0.01$ versus all other groups; ${ }^{* * *} p<0.001$ versus all other groups. Numbers above bars represent the number of independent observations per group.
NO release from median eminence endothelial cells varies according to the endocrine condition of the animal (Prevot et al., 1999b, 2000; Knauf et al., 2001a,b) and in particular according to the circulating levels of gonadal steroids such as estradiol (Prevot et al., 1999b, 2000; Knauf et al., 2001a,b). These features and the present results suggest that vascular endothelial cells of the median eminence can sense and rapidly convey peripheral information to the neuroendocrine brain and thus profoundly influence neuron-glia communication, and hence neurosecretion, in a domain-specific manner. Conceivably, endothelial cells forming part of gliovascular units throughout the brain might be engaged in regulating (and use equivalent signaling mechanisms to regulate) neuronal activity. In keeping with this idea, a recent study suggested that vascular-neuronal signaling in the nucleus tractus solitarii, the termination site for baroreceptor afferents in the brainstem, may mediate NO-dependent inhibition of angiotensin-II-induced baroreceptor reflex (for review, see Paton et al., 2002). Activation of angiotensin-I receptors by circulating angiotensin-II stimulates eNOS activity and elicits NO release from the capillary endothelium. In turn, NO diffuses, reaching nearby GABAergic interneurons that then inhibit the neurons mediating the baroreceptor reflex (Paton et al., 2002).

In summary, our results show the existence in the neuroendocrine brain of an NO-dependent endothelium-to-glia communication system that significantly impacts neurosecretion by regulating the formation of specialized neuron-glia junctions. In a broader context, the results raise the intriguing possibility that endothelia-to-glia communication is a key element of the process by which peripheral information is transferred from the microcirculation to neurons throughout the CNS.

\section{References}

Agnati LF, Zoli M, Stromberg I, Fuxe K (1995) Intercellular communication in the brain: wiring versus volume transmission. Neuroscience 69:711-726.

Bartlett PF, Noble MD, Pruss RM, Raff MC, Rattray S, Williams CA (1981) Rat neural antigen-2 (RAN-2): a cell surface antigen on astrocytes, ependymal cells, Muller cells and lepto-meninges defined by a monoclonal antibody. Brain Res 204:339-351.

Beauvillain JC, Tramu G (1980) Immunocytochemical demonstration of LH$\mathrm{RH}$, somatostatin, and ACTH-like peptide in osmium-postfixed, resinembedded median eminence. J Histochem Cytochem 28:1014-1017.

Bredt DS (2003) Nitric oxide signaling specificity - the heart of the problem. J Cell Sci 116:9-15.

Bredt DS, Snyder SH (1992) Nitric oxide, a novel neuronal messenger. Neuron 8:3-11.

Chauvet N, Privat A, Alonso G (1996) Aged median eminence glial cell cultures promote survival and neurite outgrowth of cocultured neurons. Glia 18:211-223.

Cottrell GT, Ferguson AV (2004) Sensory circumventricular organs: central roles in integrated autonomic regulation. Regul Pept 117:11-23.

Dziedzic B, Prevot V, Lomniczi A, Jung H, Cornea A, Ojeda SR (2003) Neuron-to-glia signaling mediated by excitatory amino acid receptors regulates ErbB receptor function in astroglial cells of the neuroendocrine brain. J Neurosci 23:915-926.

Edgell CJ, McDonald CC, Graham JB (1983) Permanent cell line expressing human factor VIII-related antigen established by hybridization. Proc Natl Acad Sci USA 80:3734-3737.

Gally JA, Montague PR, Reeke Jr GN, Edelman GM (1990) The NO hypothesis: possible effects of a short-lived, rapidly diffusible signal in the development and function of the nervous system. Proc Natl Acad Sci USA 87:3547-3551.

Hardy TA, May JM (2002) Coordinate regulation of L-arginine uptake and nitric oxide synthase activity in cultured endothelial cells. Free Radic Biol Med 32:122-131.

Hatton GI (1997) Function-related plasticity in hypothalamus. Annu Rev Neurosci 20:375-397. 
Haydon PG (2001) GLIA: listening and talking to the synapse. Nat Rev Neurosci 2:185-193.

Hemmings Jr HC, Greengard P (1986) DARPP-32, a dopamine- and adenosine $3^{\prime}: 5^{\prime}$-monophosphate-regulated phosphoprotein: regional, tissue, and phylogenetic distribution. J Neurosci 6:1469-1481.

King JC, Letourneau RJ (1994) Luteinizing hormone-releasing hormone terminals in the median eminence of rats undergo dramatic changes after gonadectomy, as revealed by electron microscopic image analysis. Endocrinology 134:1340-1351.

Knauf C, Prevot V, Stefano GB, Mortreux G, Beauvillain JC, Croix D (2001a) Evidence for a spontaneous nitric oxide release from the rat median eminence: influence on gonadotropin-releasing hormone release. Endocrinology 142:2343-2350.

Knauf C, Ferreira S, Hamdane M, Mailliot C, Prevot V, Beauvillain JC, Croix D (2001b) Variation of endothelial nitric oxide synthase synthesis in the median eminence during the rat estrous cycle: an additional argument for the implication of vascular blood vessel in the control of GnRH release. Endocrinology 142:4288-4294.

Koesling D, Friebe A (1999) Soluble guanylyl cyclase: structure and regulation. Rev Physiol Biochem Pharmacol 135:41-65.

Kozlowski GP, Coates PW (1985) Ependymoneuronal specializations between LHRH fibers and cells of the cerebroventricular system. Cell Tissue Res 242:301-311.

Levine JE, Ramirez VD (1982) Luteinizing hormone-releasing hormone release during the rat estrous cycle and after ovariectomy, as estimated with push-pull cannulae. Endocrinology 111:1439-1448.

Lindberg RA, Dewhirst MW, Buckley BJ, Hughes CS, Whorton AR (1996) $\mathrm{Ca}(2+)$-dependent nitric oxide release in endothelial but not R3230Ac rat mammary adenocarcinoma cells. Am J Physiol 271:C332-C337.

Lino M, Goto K, Kakegawa W, Okado H, Sudo M, Ishiuchi S, Miwa A, Takayasu Y, Saito I, Tsuzuki K, Ozawa S (2001) Glia-synapse interaction through $\mathrm{Ca}^{2+}$-permeable AMPA receptors in Bergmann glia. Science 292:926-929.

Meister B, Hokfelt T, Tsuruo Y, Hemmings H, Ouimet C, Greengard P, Goldstein M (1988) DARPP-32, a dopamine- and cyclic AMP-regulated phosphoprotein in tanycytes of the mediobasal hypothalamus: distribution and relation to dopamine and luteinizing hormone-releasing hormone neurons and other glial elements. Neuroscience 27:607-622.

Mi H, Barres BA (1999) Purification and characterization of astrocyte precursor cells in the developing rat optic nerve. J Neurosci 19:1049-1061.

Mi H, Haeberle H, Barres BA (2001) Induction of astrocyte differentiation by endothelial cells. J Neurosci 21:1538-1547.

Nedergaard M, Ransom B, Goldman SA (2003) New roles for astrocytes: redefining the functional architecture of the brain. Trends Neurosci 26:523-530.

Nishiyama M, Hoshino A, Tsai L, Henley JR, Goshima Y, Tessier-Lavigne M, Poo MM, Hong K (2003) Cyclic AMP/GMP-dependent modulation of $\mathrm{Ca}^{2+}$ channels sets the polarity of nerve growth-cone turning. Nature 424:990-995.

Ojeda SR, Prevot V, Heger S, Lomniczi A, Dziedzic B, Mungenast A (2003) Glia-to-neuron signaling and the neuroendocrine control of female puberty. Ann Med 35:244-255.

Oliet SH, Piet R, Poulain DA (2001) Control of glutamate clearance and synaptic efficacy by glial coverage of neurons. Science 292:923-926.

Ouimet CC, Miller PE, Hemmings Jr HC, Walaas SI, Greengard P (1984) DARPP-32, a dopamine- and adenosine $3^{\prime}: 5^{\prime}$-monophosphate-regulated phosphoprotein enriched in dopamine-innervated brain regions. III. Immunocytochemical localization. J Neurosci 4:111-124.

Palkovitz M (1987) Summary of structural and functional aspects of the circumventricular organs. In: Circumventricular organs and body fluids (Gross PM, ed), pp 209-218. Boca Raton, FL: CRC.

Parpura V, Haydon PG (2000) Physiological astrocytic calcium levels stimulate glutamate release to modulate adjacent neurons. Proc Natl Acad Sci USA 97:8629-8634.

Paton JF, Kasparov S, Paterson DJ (2002) Nitric oxide and autonomic control of heart rate: a question of specificity. Trends Neurosci 25:626-631.
Paxinos G, Watson C (1982) The rat brain in stereotaxic coordinates. New York: Academic.

Prevot V, Dutoit S, Croix D, Tramu G, Beauvillain JC (1998) Semiquantitative ultrastructural analysis of the localization and neuropeptide content of gonadotropin releasing hormone nerve terminals in the median eminence throughout the estrous cycle of the rat. Neuroscience 84:177-191.

Prevot V, Croix D, Bouret S, Dutoit S, Tramu G, Stefano GB, Beauvillain JC (1999a) Definitive evidence for the existence of morphological plasticity in the external zone of the median eminence during the rat estrous cycle: implication of neuro-glio-endothelial interactions in gonadotropinreleasing hormone release. Neuroscience 94:809-819.

Prevot V, Croix D, Rialas CM, Poulain P, Fricchione GL, Stefano GB, Beauvillain JC (1999b) Estradiol coupling to endothelial nitric oxide stimulates gonadotropin-releasing hormone release from rat median eminence via a membrane receptor. Endocrinology 140:652-659.

Prevot V, Bouret S, Stefano GB, Beauvillain J (2000) Median eminence nitric oxide signaling. Brain Res Brain Res Rev 34:27-41.

Prevot V, Rio C, Cho GJ, Lomniczi A, Heger S, Neville CM, Rosenthal NA, Ojeda SR, Corfas G (2003a) Normal female sexual development requires neuregulin-erbB receptor signaling in hypothalamic astrocytes. J Neurosci 23:230-239.

Prevot V, Cornea A, Mungenast A, Smiley G, Ojeda SR (2003b) Activation of erbB-1 signaling in tanycytes of the median eminence stimulates transforming growth factor $\beta 1$ release via prostaglandin E2 production and induces cell plasticity. J Neurosci 23:10622-10632.

Prevot V, De Seranno S, Estrella C (2004) Glial-neuronal-endothelial interactions and the neuroendocrine control of GnRH secretion. In: Nonneuronal cells of the nervous system: function and dysfunction (Hertz L, ed), pp 199-214. Amsterdam: Elsevier.

Richardson A, Malik RK, Hildebrand JD, Parsons JT (1997) Inhibition of cell spreading by expression of the C-terminal domain of focal adhesion kinase (FAK) is rescued by coexpression of Src or catalytically inactive FAK: a role for paxillin tyrosine phosphorylation. Mol Cell Biol 17:6906-6914.

Rutzel H, Schiebler TH (1980) Prenatal and early postnatal development of the glial cells in the median eminence of the rat. Cell Tissue Res 211:117-137.

Salvemini D, Misko TP, Masferrer JL, Seibert K, Currie MG, Needleman P (1993) Nitric oxide activates cyclooxygenase enzymes. Proc Natl Acad Sci USA 90:7240-7244.

Schmidt A, Hall MN (1998) Signaling to the actin cytoskeleton. Annu Rev Cell Dev Biol 14:305-338.

Seidel C, Bicker G (2000) Nitric oxide and cGMP influence axonogenesis of antennal pioneer neurons. Development 127:4541-4549.

Simard M, Arcuino G, Takano T, Liu QS, Nedergaard M (2003) Signaling at the gliovascular interface. J Neurosci 23:9254-9262.

Song H, Ming G, He Z, Lehmann M, McKerracher L, Tessier-Lavigne M, Poo M (1998) Conversion of neuronal growth cone responses from repulsion to attraction by cyclic nucleotides. Science 281:1515-1518.

Tapon N, Hall A (1997) Rho, Rac and Cdc42 GTPases regulate the organization of the actin cytoskeleton. Curr Opin Cell Biol 9:86-92.

Theodosis DT (2002) Oxytocin-secreting neurons: a physiological model of morphological neuronal and glial plasticity in the adult hypothalamus. Front Neuroendocrinol 23:101-135.

Turner CE (2000) Paxillin and focal adhesion signaling. Nat Cell Biol 2:E231-E236.

Wark BJ, Ullian EM, Harris BT, Barres BA (2002) Astrocytes integrate neural activity in regulating formation of synapses in vitro. Soc Neurosci Abstr 28:331.2.

Yano H, Uchida H, Iwasaki T, Mukai M, Akedo H, Nakamura K, Hashimoto S, Sabe H (2000) Paxillin alpha and Crk-associated substrate exert opposing effects on cell migration and contact inhibition of growth through tyrosine phosphorylation. Proc Natl Acad Sci USA 97:9076-9081.

Zonta M, Angulo MC, Gobbo S, Rosengarten B, Hossmann KA, Pozzan T, Carmignoto G (2003) Neuron-to-astrocyte signaling is central to the dynamic control of brain microcirculation. Nat Neurosci 6:43-50. 